\title{
'Putting Radiohead Next to Bach.' Perceptions of Cultural Hierarchy Unravelled with a Ranking Task
}

\author{
Marcel van den Haak ${ }^{1 *}$ \\ ${ }^{1}$ Radboud University Nijmegen, NETHERLANDS \\ *Corresponding Author: marcelvandenhaak@hotmail.com \\ Citation: van den Haak, M. (2020). 'Putting Radiohead Next to Bach.' Perceptions of Cultural Hierarchy \\ Unravelled with a Ranking Task, Journal of Cultural Analysis and Social Change, 5(1), 02. \\ https://doi.org/10.20897/jcasc/8265
}

Published Online: May 15, 2020

\begin{abstract}
Although cultural hierarchy is a social construction - the result of ever changing distinction practices by elites - the consequential division between 'high culture' and 'low culture' is often either taken for granted as a fixed opposition, or disputed because of waning boundaries. To what extent individuals of different status groups adhere to such hierarchy is not known, nor whether changed cultural taste patterns result in alternate perceptions. This article aims to unravel cultural taste, perceptions of and opinions on cultural hierarchy, by means of a ranking task with musical items among ninety people in the Netherlands. It shows, first, that perceptions of cultural hierarchy are still sound among many, regardless of egalitarian opinions. Second, many distinguish personal tastes - which are evidently diverse - from their perceptions of cultural hierarchy - on which a certain agreement exists. Third, this agreement is not absolute, as there are several deviations, that are related to educational level and age.
\end{abstract}

Keywords: cultural hierarchy, cultural taste, high culture, low culture, ranking method

\section{INTRODUCTION}

The concepts 'high culture' and 'low culture' are frequently used in the cultural field and the media, as well as in cultural sociology. They indicate a hierarchical organisation of cultural artefacts, in a more or less homologous relation with the social hierarchy of their audiences (cf. Bourdieu, 1984). Most users will share some common sense knowledge of these concepts' meanings - classical music is considered high culture, soap operas are low culture even though these categories cannot be objectively defined and demarcated. They are social constructions, the result of distinction practices among upper and middle classes as well as valuation processes by consecrating institutions (Bourdieu, 1984, 1996).

The question arises, though, whether this implies that members of the upper and upper-middle classes fully realize the social status of their taste, in other words, to what extent they equate their own taste with high culture and their dislikes with low culture, or whether the picture is more complex. Do members of lower classes, in their turn, implicitly acknowledge their own inferior position in social and cultural hierarchy, as Bourdieu (1984: 372396) claimed, or are they hardly aware of others' distinction practices? Perceptions of cultural hierarchy have never been empirically studied (cf. Robette and Roueff, 2014).

Such questions have become more salient in recent decades, as both social and cultural hierarchy have become more and more disputed. In many Western societies, including the Netherlands, social stratification as such came under fire on moral grounds, favouring more egalitarian and individualist stances (e.g., Wouters 2007; Van Eijk 2013). The significance of cultural hierarchy is contested, as boundaries between high and low are blurring among 
both producers and consumers of art. When 'postmodern' artists deliberately mix items from high and low culture, when popular culture gains prestige among consecrating institutions (Baumann 2001; Van Venrooij \& Schmutz 2010) and when 'highbrow' consumers turn into 'cultural omnivores' with broad, boundary-crossing tastes (e.g., Peterson and Kern, 1996), the relevance of the concepts 'high culture' and 'low culture' seems to vanish.

However, distinction processes as such did not cease to occur, as some early scholars on omnivorousness expected (Peterson and Kern, 1996; Ollivier, 2008). For instance, high-low distinctions are often made within popular genres, based on different modes of consumption (Holt, 1998; Jarness, 2015). The logical consequence of this ongoing process would be the continuation of cultural hierarchy, albeit with less clear demarcations and less agreement on the exact nature of high and low culture (cf. Van den Haak, 2018a).

Therefore, the question can be raised what effect such changes have on an overall cultural hierarchy. Might, for instance, a classic rock band such as The Beatles nowadays be equated with Bach or Mozart? And what about the status of young well-educated listeners' preferences within popular contemporary music genres such as hip hop and EDM? Naturally, this article does not aim to 'objectively' answer these questions, but instead looks at various people's perceptions of and opinions on cultural hierarchy. It asks the question to what extent there is a shared sense of cultural hierarchy, how these hierarchical perceptions are related to personal preferences and dislikes, and how potential deviations from this shared sense can be explained.

The questions will be answered by means of an innovative research design in this field: a ranking task on the specific domain of music. As part of in-depth interviews on cultural taste, distinction and hierarchy, a diverse sample of ninety people in the Netherlands was asked to rank thirty cards with the names of composers, musicians, singers and bands, both in order of their own taste preference, and according to their perception of high and low culture. In addition to an explorative quantitative analysis of these rankings, respondents' verbal clarifications reveal both their legitimations and their attitudes on the exercise as such.

After a further theoretical exploration and a discussion of the research methods, the results section will show that most respondents - regardless of their opinion on the concept of hierarchy as such - perceive a cultural hierarchy with regard to music, which to a greater or lesser extent deviates from personal taste rankings. The article will explore the shared sense of this hierarchy, as well as several deviations that are related to educational level and age.

\section{THE INTERRELATION BETWEEN CULTURAL TASTE AND HIERARCHY}

Cultural taste - here defined as individuals' preferences and dislikes for certain cultural artefacts - is related to cultural hierarchy in mutual ways. On the one hand, hierarchy shapes tastes. Individuals' preferences and aversions are strongly influenced by one's upbringing and school education, which are class related. The volume and form of their cultural capital inform their habitus, which in its turn shapes their preferences. This works both directly young members of higher classes are taught the canonized works from art history - and, moreover, indirectly they learn to value cultural items for aesthetic qualities that are deemed important, particularly to favour form over function and to detach from their initial emotions. Conversely, a working-class habitus leads to a 'popular aesthetic', with less emotional detachment and favouring function over form (Bourdieu, 1984).

On the other hand, tastes shape hierarchy. The habitus works in two ways: it is both 'a structuring and structured structure' (ibid.: 170). People with a high volume of cultural capital distinguish themselves with their tastes and lifestyle from those with less cultural capital, i.e. members of middle and lower classes as well as elites with relatively more economic capital. They acquire social status by means of their cultural preferences and practices, they recognise each other and thereby exclude others from their circles. Imitation practices by members of the middle and lower classes lead to further distinction, which continuously reproduces cultural hierarchy, regardless of dynamics in its exact form. This constant reproduction is further established through the recognition by middleand lower-class people of their intermediate or inferior position, Bourdieu claims.

Hence, cultural hierarchy is a social construction, that in its turn greatly shapes people's everyday practices. It has such a strong discursive power that it can easily be perceived as objectively true and universal, as if objects possess actual qualities that make them 'high culture'. This misconception is strengthened by the alleged complexity of high culture, which contributes to the notion that it can be best understood by the well-educated, or perhaps solely by specialised connoisseurs. The alternative term 'highbrow', originally derived from late-nineteenth-century phrenological practices, even refers directly to one's intellectual capacities (Levine, 1988: 221-223). Furthermore, 'consecrating institutions', such as museums, quality newspapers and universities, have been attributed the power - the 'symbolic capital' - to decide which cultural disciplines, genres or specific artists are eligible to enter the canon of high culture (Bourdieu 1996, Baumann 2001). Hence, the status of cultural items results from complex power dynamics and interactions between different actors in the cultural field: producers, different types of intermediaries and art consumers (ibid.). 
What we do not know, however, is to what extent people of different backgrounds actually perceive a cultural hierarchy, and how this is related to their personal preferences and dislikes. Notwithstanding a vast amount of sociological literature on taste patterns as such, in which cultural hierarchy is either presumed a priori (e.g., Peterson and Kern, 1996) or deducted from data on taste and distinction (e.g., Warde 2011) - with highly diverse outcomes (Brisson, 2019; Robette and Roueff, 2014) - , perception of cultural hierarchy has not been discussed. Although one might say that individuals with a high volume of cultural capital practise cultural hierarchy as they distinguish themselves from others, this does not necessarily occur explicitly and consciously, with the deliberate intent to place their own preferences on a pedestal (Bourdieu, 1984). We do not know to what extent they actually perceive their taste as having a high position in a cultural hierarchy.

Similarly, Bourdieu did not provide clear evidence for his claim that working-class people acknowledge their inferior position in this hierarchy. His ideas have often been contested. Rather than accepting high culture's status, another plausible attitude would be one of indifference - lower class people simply like or dislike certain tastes without attaching status consequences (Michael, 2017: 97-130) - or ambivalence (Bennett et al., 2009: 209-212; cf. Kuipers, 2006: 77). Moreover, they often distinguish themselves from higher classes on moral rather than cultural or economic grounds (Lamont, 2000; Van Eijk, 2013; Van den Haak and Wilterdink, 2019).

Finally, if people perceive cultural hierarchy, we do not know what it exactly looks like. People might attribute entire domains to either high or low culture, or make certain distinctions within such domains. Nor do we know what grounds their perceptions: are these related to social hierarchy, or to alleged characteristics of cultural artefacts, such as complexity and originality?

\section{INCREASED COMPLEXITIES IN LESS HIERARCHICAL TIMES}

What further complicates the abovementioned questions is the alleged waning of boundaries between high and low culture in the second half of the twentieth and the twenty-first century. Cultural hierarchy is increasingly being contested. In cultural sociology, this notion has been linked to the rise of 'cultural omnivores': literally people who like or consume everything, but mostly defined as those individuals who like a large diversity of cultural items, particularly transgressing boundaries between high and low culture (e.g., Peterson and Simkus, 1992).

This phenomenon is related to several processes. First, it can be linked with the decline of social stratification as such. In several Western countries strong and rigid hierarchies have been replaced by more egalitarian social relations. Associations between classes became less unequal, less authoritarian and less formal; in the Netherlands these changes were even more extreme than elsewhere (Wouters, 2007). The shift was caused both by increased resentment and active resistance by underprivileged groups and by an egalitarian and individualist ideology among - often younger - members of more dominant groups (such as the 1960s' counterculture).

Second, the participation in what is usually perceived as high culture declined (e.g., Van Eijck et al., 2002), and so did its symbolic value (Prieur and Savage, 2013). This 'desacralisation' of high culture is related to changes in the educational system, in which the old humanistic ideal of Bildung lost importance. Third, popular subcultures increased sharply since the late 1950s and eventually outgrew their original youth audience. Popular music is increasingly being taken seriously by consecrating institutions (Janssen et al. 2011; Van Venrooij and Schmutz 2010). Nevertheless, 'popular culture' has eclipsed low culture as a more common antonym of high culture. ${ }^{1}$

But what do these historical changes mean for the perception of cultural hierarchy? Does the increased significance of egalitarian opinions imply that hierarchy is no longer perceived at all, or do critics just reject what they do perceive? The assumed waning of cultural hierarchy makes the relation between taste, hierarchy and distinction (as a mediating mechanism) more complex.

First, the relation between taste and bierarchy as such became more complex. Cultural omnivores were often defined as - mostly high-status - individuals who combine high and low culture into a mixed taste pattern and who hence transgress these domains. Such a priori categorisations were particularly applied in some early omnivore studies (e.g., Emmison, 2003; López Sintas and García Álvarez, 2004; Peterson, 1992; Peterson and Kern, 1996; Van Eijck et al., 2002). Later, concepts such as 'high culture' or 'highbrow consumers' were inferred from taste patterns among certain status groups (e.g., Warde, 2011), for instance by means of factor, cluster or multiple correspondence analysis (e.g., Coulangeon, 2013b; Elchardus and Siongers, 2007; Prieur et al., 2008; Van Eijck, 2001). ${ }^{2}$ Yet, if high status consumers have boundary-crossing tastes, the relevance of separate domains - high culture as the preferences of high status groups - disappears.

Second, the relation between taste and distinction became more complex. Omnivorousness was initially often interpreted as a high degree of openness and tolerance for others' tastes (Bryson, 1996; Ollivier, 2008; Peterson

\footnotetext{
${ }^{1}$ Several scholars describe a triangle of high, popular and folk (low) culture (Schulze 1992; cf. Frith 1996: 36-42; Van Eijck \& Lievens 2008).

${ }^{2}$ See for a critical overview: Robette \& Roueff 2014 (cf. Brisson 2019).
} 
and Kern, 1996), and hence as a near absence of cultural distinction. Later scholars, however, provided clues for the distinctive value of a broad taste as such (Van Eijck, 2000; Prieur and Savage, 2013) and of 'voraciousness' of cultural activities of whichever kind (Coulangeon, 2013a). Both interpretations make cultural hierarchy as a ranking of cultural artefacts irrelevant.

Third, the relation between distinction and bierarchy became more complex. Contemporary consumers not only distinguish themselves based on breadth and voraciousness, but also traditionally with their taste as such, yet within popular culture. It is how they perceive it what matters, rather than what they like exactly (Holt, 1998; Jarness, 2015; Van den Haak, 2018b). High status people apply an aesthetic disposition both to distinguish high from popular culture and to explain their preferences within popular culture, such as 'complex' hip hop or 'innovative' EDM (Thornton, 1995; cf. Bachmayer et al., 2014). Furthermore, new evaluation criteria might gain importance over time, as the mentioned 'aesthetic disposition' is historically situated; the product of a specific modernist discourse that may evolve (Hanquinet, 2018). Members of different status groups can even enjoy the exact same object with divergent attitudes, such as a serious versus an ironic one (Peters et al., 2018; cf. Friedman, 2012; Jarness, 2015). Classical music is not necessarily higher than hip hop, but higher status fans of classical music and hip hop make choices based on roughly the same logic within both genres. This does imply a sort of cultural hierarchy, yet with perceived complex and innovative items of any kind on top, which would lead to a less straightforward picture.

Due to this complex situation, the question to what extent people of different backgrounds perceive a cultural hierarchy, and if so, what this hierarchy looks like and on what grounds it is formed, becomes even more relevant. The perceived hierarchy might be more 'traditional' or map more closely on the current taste preferences of high status groups. Perhaps people are not willing to hierarchically rank cultural items, or do not understand such vertical categorisation at all. Besides differences between status groups, age might play a role, as younger cohorts could be more inclined to confer status to certain forms of popular music. This research provides new insights into concepts that are too often defined by researchers themselves.

\section{DATA AND METHODS}

The data presented in this article were collected in the context of a more encompassing research project, based on in-depth interviews with ninety people in the Netherlands. They were asked questions about their cultural likes and dislikes vis-à-vis significant others, within a wide range of cultural disciplines. This article examines the final part of each interview, a ranking task on the specific field of music, which is analysed in a quantitative yet explorative way. While ranking tasks are not unique in sociological research, they have not been used in studies on cultural taste; this study is inspired by classical Dutch research on the ranking of occupational prestige (Sixma and Ultee, 1983; Van Heek and Vercruijsse, 1958).

Respondents were requested to rank thirty items, printed on small cards, twice: in the order of their personal taste and according to their perception of a cultural hierarchy. The latter was phrased as: "Could you rank the items from high to low culture, as you think they are perceived in society?"3 The task was preceded by open questions on respondents' associations with the concepts 'high culture' and 'low culture'. Half of the respondents, randomly assigned, were asked to begin with the hierarchical ranking and to perform the taste ranking second, in order to correct for possible follow-up effects: a hierarchy strongly influenced by taste. However, the sequence in which the two tasks were performed did not have an effect on the rankings. ${ }^{4}$ Respondents were encouraged to put items unknown to them aside. The number of cards that were included in the taste ranking ranged from only 12 to all 30 , with a mean of 23.4 and a standard deviation of 3.9. ${ }^{5}$ On request, respondents were allowed to form small groups of cards, in which case the mean ranking of these items was coded. ${ }^{6}$

\section{The Selection of Items}

In studies on cultural taste, respondents are often asked to give their opinion on a selection of (musical) genres (e.g., Bryson, 1996; Peterson and Kern, 1996). However, genres are too broad and often diverse categories, while genre boundaries are both contested (Atkinson, 2011; Holt, 1997; Savage, 2006) and dynamic (Lena and Peterson, 2008). Other scholars avoid these disadvantages by asking questions on specific musical pieces or songs (Bourdieu,

\footnotetext{
${ }^{3}$ In the first few interviews, respondents were asked about their perception of the items' status in society, but this was soon altered in order to avoid misunderstandings about the meaning of both 'status' and 'society'.

4 The items' mean hierarchical rankings did not significantly correlate with the question which task was performed first. Furthermore, the mean 'deviation measure' (see section 'The relation between taste and hierarchical perception') is 0.21 when taste is asked first and 0.18 when hierarchy is asked first, which is not a significant difference either.

${ }^{5}$ The number of included cards correlates negatively with age (Pearson's $r$ is $-.57 ; p<.01$ ), due to the large proportion of popular music items in the list. There is no relation with educational level or gender.

${ }^{6}$ For instance, when the upper 3 were grouped together, all 3 items were coded as " 2 ". In those rare cases when cards were categorized in only 2 or 3 large groups, results were not coded.
} 
1984; Bennett et al., 2009). This solution, though, might lead to more missing values than necessary, as one might not recognise a certain title by an otherwise familiar composer. Therefore, an intermediate position was taken, by using the names of individual composers and performers (singers, musicians, bands) from several but not all possible genres (cf. Nagel et al., 2011). This turned out to be a manageable solution for most respondents; only rarely doubts were expressed about an artist's diverse oeuvre (for instance, how to rank Metallica when disliking their music, except for their hit ballad 'Nothing else matters'?).

The selected items cover a broad range of music genres and are diverse with regard to several potentially relevant characteristics: time period, country of origin, gender, reputation in the field (based on features such as perceived complexity, craftsmanship, authenticity) and the degree of familiarity among a large audience. For instance, it features five classical composers, including the highly consecrated Johann Sebastian Bach, the more complex and less well-known Arnold Schönberg and the more popular and easily digestible Johann Strauss II. Naturally, this list is imperfect and by definition incomplete, while features such as complexity and authenticity cannot be attributed objectively. However, the analysis will be explorative rather than testing hypotheses on, for instance, the 'effect' of complexity.

In order to test respondents' trustworthiness and attentiveness, one fictitious name was included: J. Pirakovich. Only five respondents included this item in their rankings, mostly in intermediate positions. This item is excluded from further analyses. The list includes six items originated from the Netherlands, which will be further explained when necessary.

\section{The Sample}

Because the overall study was aimed at comparing demographic groups rather than generating a representative sample, a quota sample was designed. The quotas consisted of three birth cohorts (before 1945, 1945-'65, 1965'85) and three status groups (well-educated with well-educated parents, well-educated with less-educated parents, less-educated with less-educated parents), resulting in nine quotas of ten people each, equally distributed over males and females. ${ }^{7}$ Educational level was categorised 'high' when one has a university or higher vocational education ( $\mathrm{HBO})$; and low when one has at most medium vocational education (MBO). As parents' education did not turn out to be relevant for our current study, in the remainder of this article only respondents' educational level will be taken into account, measured on a 4-point scale. ${ }^{8}$

Online postal code and phone directories were used to draw a random sample in order to gradually fill the quotas. ${ }^{9}$ The interviews took place in 2009 and 2010 in both urban, suburban and rural areas in the North-West of the Netherlands, including Amsterdam. The taste ranking was performed by 85 out of 90 respondents; the hierarchy ranking by 77 . The somewhat higher number of missing values on the latter was caused by a diversity of issues, such as fatigue and the unwillingness or incapability to rank items hierarchically (discussed below). The oldest birth cohort is slightly underrepresented in the ranking task, compared to the entire sample.

\section{RESULTS}

\section{Distinguishing Perception, Knowledge and Opinion}

Before turning to the analysis of the rankings as such, the ranking practice itself must be discussed. As mentioned, only a few respondents did not rank the items hierarchically due to either lack of knowledge or resistance. Most others did perform the task, even though some of them shared this lack of knowledge or resistance. First, some respondents - relatively often with a low educational level - did not know the concept 'high culture'. Michiel ${ }^{10}$ heard 'this term for the first time', Didi found it a 'strange description', and Noortje concluded that she is 'apparently not familiar with this subject'. In these cases, the assignment was rephrased as 'the status ranking in society', which more than once resulted in a ranking that closely resembled the rankings of more knowledgeable respondents after all. A similar resemblance was found among nineteen uninformed respondents who guessed the concept's meaning, as its separate components 'high' and 'culture' are not difficult to grasp.

\footnotetext{
${ }^{7}$ Gender will not be discussed further, as significant differences between men and women are rare: with only two items in the taste ranking and one item in the perceived hierarchy.

8 1: academic; 2: HBO (higher vocational); 3: MBO (medium vocational); 4: below MBO.

${ }^{9}$ When, after some time, certain quotas remained difficult to fill, random samples were drawn from purposefully selected postal codes that, according to government statistics, contain high numbers from certain age groups and/or income levels (used as a proxy for educational level). Eventually, the average response rate was about $25 \%$. Only the last fifteen empty spaces were filled by drawing upon the researcher's own diverse network, such as a friend's mother. See Van den Haak (2014: pp. 78-88) for more details on the sampling procedure.

${ }^{10}$ All names are pseudonyms; all quotes are translated from Dutch.
} 
Table 1. Mean hierarchy scores, compared with mean taste scores

\begin{tabular}{|c|c|c|c|c|c|c|c|}
\hline & \multirow[t]{2}{*}{$\begin{array}{l}\text { familiar } \\
(\mathrm{N}=85)\end{array}$} & \multicolumn{3}{|c|}{$\begin{array}{c}\text { hierarchy ranking } \\
(\mathbf{N}=77)\end{array}$} & \multicolumn{3}{|c|}{$\begin{array}{l}\text { taste ranking } \\
(\mathrm{N}=85)^{12}\end{array}$} \\
\hline & & position & $\begin{array}{l}\text { mean } \\
\text { score }\end{array}$ & $\begin{array}{l}\text { standard } \\
\text { deviation }\end{array}$ & position & $\begin{array}{l}\text { mean } \\
\text { score }\end{array}$ & $\begin{array}{l}\text { standard } \\
\text { deviation }\end{array}$ \\
\hline J.S. Bach & 85 & 1 & 90.5 & 20.2 & 2 & 66.9 & 32.5 \\
\hline W.A. Mozart & 85 & 2 & 88.7 & 17.6 & 4 & 64.2 & 30.7 \\
\hline A. Vivaldi & 81 & 3 & 81.1 & 20.8 & 6 & 63.7 & 31.5 \\
\hline A. Schönberg* & 41 & 4 & 80.8 & 14.4 & 12 & 57.6 & 31.0 \\
\hline Johann Strauss II & 84 & 5 & 74.6 & 22.1 & 18 & 49.3 & 24.1 \\
\hline Jacques Brel & 80 & 6 & 66.6 & 17.7 & 3 & 65.2 & 24.5 \\
\hline Ella Fitzgerald & 69 & 7 & 65.5 & 19.4 & 9 & 60.2 & 23.8 \\
\hline The Beatles & 85 & 8 & 64.1 & 19.4 & 1 & 69.7 & 22.2 \\
\hline Glenn Gould* & 33 & 9 & 59.8 & 27.4 & 16 & 53.8 & 27.5 \\
\hline John Coltrane & 45 & 10 & 59.3 & 21.8 & 8 & 62.0 & 23.6 \\
\hline Aretha Franklin & 66 & 11 & 58.4 & 16.6 & 7 & 62.4 & 21.2 \\
\hline Wibi Soerjadi & 82 & 12 & 55.9 & 25.6 & 20 & 41.5 & 23.3 \\
\hline Ramses Shaffy & 85 & 13 & 54.1 & 18.2 & 17 & 52.3 & 23.9 \\
\hline Pink Floyd & 71 & 14 & 53.5 & 19.7 & 15 & 54.3 & 27.9 \\
\hline Rolling Stones & 84 & 15 & 53.0 & 20.4 & 11 & 57.9 & 26.0 \\
\hline Tori Amos* & 26 & 16 & 49.3 & 22.8 & 14 & 54.7 & 27.4 \\
\hline Norah Jones & 53 & 17 & 46.7 & 16.5 & 5 & 63.4 & 26.2 \\
\hline Radiobead* & 35 & 18 & 41.9 & 25.5 & 10 & 59.3 & 36.3 \\
\hline ABBA & 83 & 19 & 41.5 & 23.6 & 13 & 57.4 & 28.0 \\
\hline André Rieu & 85 & 20 & 40.2 & 26.9 & 23 & 35.8 & 26.5 \\
\hline Céline Dion & 68 & 21 & 36.0 & 18.9 & 21 & 41.1 & 27.9 \\
\hline Tiësto & 63 & 22 & 30.4 & 20.6 & 22 & 37.2 & 31.0 \\
\hline Marco Borsato & 85 & 23 & 27.6 & 18.9 & 19 & 41.5 & 29.8 \\
\hline Metallica & 57 & 24 & 26.4 & 19.7 & 25 & 34.3 & 30.4 \\
\hline Dolly Parton & 72 & 25 & 25.3 & 16.7 & 24 & 35.5 & 23.4 \\
\hline Britney Spears & 70 & 26 & 19.6 & 15.2 & 28 & 27.6 & 22.9 \\
\hline 50 Cent & 43 & 27 & 17.4 & 15.2 & 27 & 31.1 & 27.0 \\
\hline André Hazes & 85 & 28 & 15.9 & 18.9 & 26 & 32.7 & 29.2 \\
\hline Frans Bauer & 85 & 29 & 13.5 & 19.6 & 29 & 24.9 & 25.9 \\
\hline
\end{tabular}

Hence, perception of cultural hierarchy is not limited to those who are familiar with the specific concepts used in the phrasing of the task.

Second, many respondents disagreed with cultural hierarchy as such. The open interview question on associations with high and low culture, prior to the ranking task, was often met with resistance, particularly among well-educated people with egalitarian ideals (cf. Vander Stichele, 2007: 339-340). The use of the label 'high culture' is called 'arrogant', 'pretentious', 'elitist' and 'hot air'; the term 'low culture' is characterised as 'disparaging', 'discriminating' and 'mean' (see also Van den Haak and Wilterdink, 2019). However, most of them agreed to put aside their resistance in order to perform the ranking task anyway. Hence, perceptions of cultural hierarchy should be analytically separated from opinions on the matter. ${ }^{11}$ The discourse of cultural hierarchy is pervasive, regardless of specific knowledge or negative feelings. After all, one must perceive something to be able to reject it.

\section{The Mean Hierarchy}

The left side of Table 1 presents the mean hierarchy - ranked from high to low - as perceived by all 77 respondents who performed the ranking task. It must be kept in mind that the non-randomness of the sample, with a deliberate overrepresentation of the well-educated, makes this table only indicative. The first column, shows the number of respondents that included each item in their taste ranking, an indication of familiarity (which does not necessarily equate profound knowledge of the music as such). The scores indicate the mean percentiles of the items in the individual rankings, meaning that 100 is the highest possible score and 0 the lowest.

\footnotetext{
${ }^{11}$ Cf. Elshout (2016) on a similar distinction with regard to occupational hierarchy.

12 The eight respondents who did not produce a hierarchy ranking were nevertheless included in the analysis of the taste ranking. Excluding them would give only minor differences.
} 
The hierarchy shows similarities with some a priori classifications in previous research: the top five is occupied by classical composers, followed by some items from the genres chanson, jazz, classic rock and soul. ${ }^{13}$ At the bottom of the ranking one finds some Dutch language singers and some more or less contemporary popular music acts (hip hop, pop, country, heavy metal, EDM). Previous literature did not show distinctions within genres, such as rock or classical music. Within the latter, musicians are ranked lower and more dispersed than composers are. Pianist Glenn Gould (\#8) is most renowned for his interpretations of Bach (\#1); violinist and conductor André Rieu (\#20) popularized light classical music such as waltzes by Strauss (\#5).

Qualitative analysis shows several legitimations for this ranking. The most common one - like a lay sociologist - is a relation to the audience's perceived social status and size: high culture is believed to comprise what (small) groups of elites prefer. Second, seniority plays an important role, meaning that high culture has 'survived the ages'. Other arguments concern perceived attributes of the cultural items themselves, particularly complexity, morality, craftsmanship and innovativeness. Contrasting logics can play a role simultaneously, for instance by first positioning classical music on top for seniority reasons and subsequently considering the innovativeness and complexity of more contemporary acts. ${ }^{14}$

Hence, on average respondents recognise a cultural hierarchy that looks partially similar to usual classifications. But how is this hierarchy related to personal taste preferences, and how much agreement is there on the exact nature of and logic behind this hierarchy?

\section{The Relation between Taste and Hierarchical Perception}

Some respondents only slightly altered their rankings during the second part of the task. They recognised their own taste rankings as almost similar to their perceived cultural hierarchy. A good example is Yme, a 64-year-old retired manager in social work. On my request to rearrange her taste ranking to one 'from high to low culture', she realised that she did not have to change much: "God, my preference is indeed highly elitist then, ha ha!" She only moved up one item, from a low to an intermediate position..$^{15}$ Conversely, Jeroen, a 25 -year-old driver, reversed his taste ranking almost entirely, for instance by significantly moving up the classical music items that he dislikes: "Well, that's the same list but exactly the other way round. Low is me, ha ha!" He personally prefers items that are generally perceived as low culture, even by himself.

The right part of Table 1 shows the mean taste rankings, which enables a thorough comparison between both rankings. The three highest ranked composers in the hierarchy - Bach, Mozart and Vivaldi - are also favoured by many, but they must now compete with The Beatles (\#1), Jacques Brel (\#3) and Norah Jones (\#5), some of whom appeared much lower in the mean hierarchy. Conversely, the highly ranked composers Schönberg and Strauss are personally preferred far less. Similar effects can be observed with the three included classical musicians. This shows that many can distinguish their own taste from their perception of a cultural hierarchy: classical music is often regarded as high culture, regardless of one's personal taste for this genre, and regardless of large differences in taste for individual composers. Conversely, certain highly beloved popular music items are perceived as less high in the hierarchy.

In contrast to the upper half, though, in the lower half of the table the differences between taste and hierarchy are much smaller. Dutch singer Frans Bauer is both liked least and perceived as the 'lowest' culture; the other items near the bottom hardly change positions either. Apparently, dislikes are often considered as low culture, whereas likes are not necessarily perceived as high culture. Many distinguish 'good' from 'high', but tend to see 'bad' and 'low' as one and the same (cf. Bryson, 1996).

In order to study shifts between the two rankings on an individual rather than an aggregate level, a deviation measure was developed. For each individual the mean deviation between the items in the two rankings was divided by the number of items included, resulting in a figure between 0 (similar rankings) and 0.5 (reverse rankings). This measure, with a mean of 0.19 , shows a strong correlation with age (Pearson's $\mathrm{r}$ is $-0.60 ; \mathrm{p}<.001$ ) and with educational level on a 4-point scale (Spearman's rho is $-0.33 ; \mathrm{p}<.01$ ). This implies that the preferences of older and well-educated respondents most closely resemble their perception of a hierarchy, whereas less-educated respondents from younger cohorts more often perceive a gap between the two. This supports Bourdieu's thesis on lower status people's recognition of their inferior position ('low is me'), even though their opinion on the matter

\footnotetext{
13 This list shares most similarities with Elchardus and Siongers (2007), but there are deviations with, for instance, Peterson and Simkus (1992), who relate rock and 'soul/blues/r\&b' to lower status groups. See Robette \& Roueff (2014) for deviations between hierarchies when applying different methods.

${ }^{14}$ See Van den Haak (2018a) for a more detailed analysis of legitimations behind hierarchical perceptions.

${ }^{15}$ Five others did not replace any card, particularly respondents who were asked to perform the hierarchy ranking prior to the taste ranking.
} 

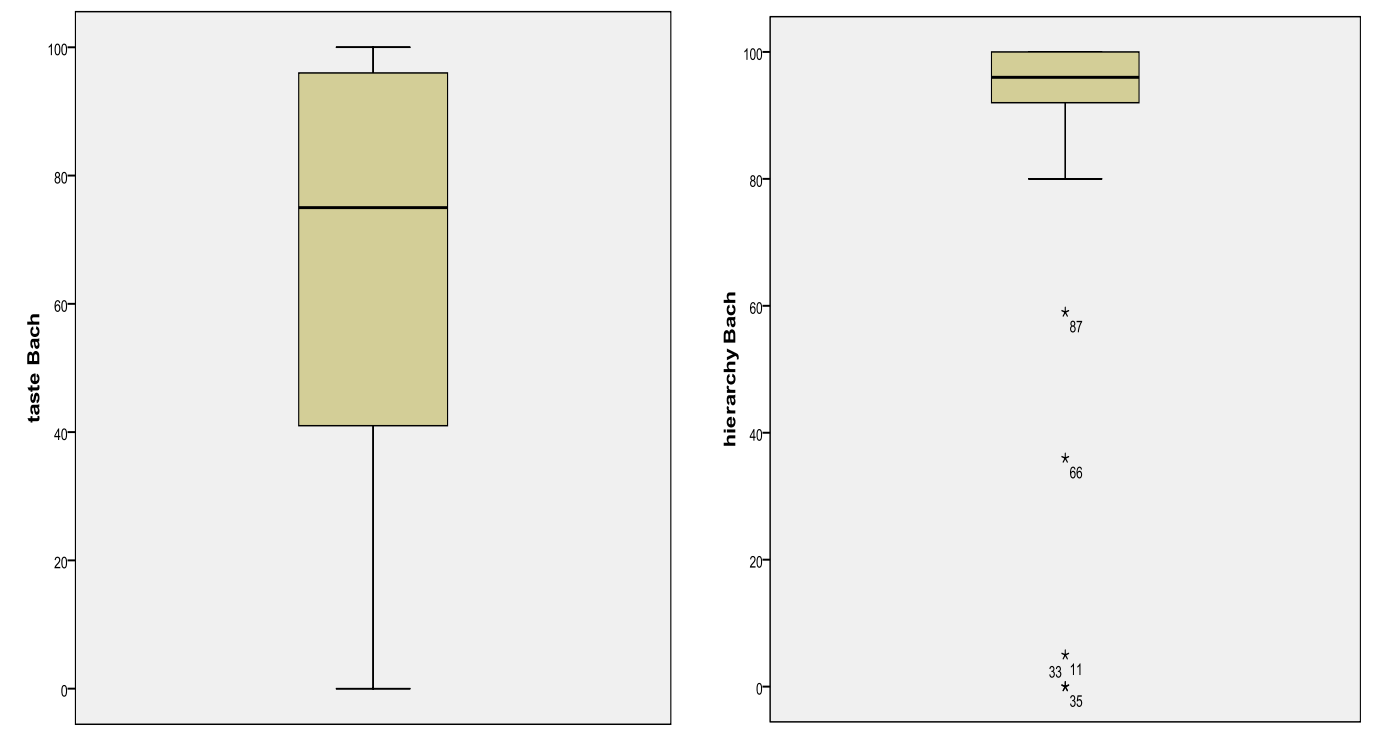

Figure 1. Box plots for the taste $(1 \mathrm{a} ; \mathrm{N}=85)$ and hierarchy rankings $(1 \mathrm{~b} ; \mathrm{N}=77)$ for J.S. Bach

might be different. ${ }^{16}$ The mean cultural hierarchy has a more or less homologous relation with the 'space of lifestyles' that Bourdieu (1984: 128-129) sketched.

\section{Agreement and Deviations on Cultural Hierarchy}

As could be expected, the agreement on cultural hierarchy is much higher than the agreement on personal tastes. Most standard deviations are lower in the hierarchy than in the taste ranking, particularly near the top and bottom positions (cf. Van Heek et al., 1958: 25-28). ${ }^{17}$ Let us take as an example the top item, Johann Sebastian Bach. The box plots in Figure 1 clearly show that the large majority of respondents position Bach in one of the top positions (1b), whereas their taste for his music is much more dispersed (1a). The dispersion of the other items' hierarchical positions is less high than this extreme example, but still on average $60 \%$ of the cards lies within a range of $15 \%$ above or below the mean score for each item. ${ }^{18}$

Evidently, this agreement is not absolute. The remainder of this section will show how deviations are related to respondents' educational level and age. Table 2 shows the rank correlations (Spearman's rho) between educational level and both the hierarchy and taste rankings per item. As the number of respondents is not high, particularly with less well-known items, only strong correlations are significant. ${ }^{19}$ The items are again presented in the order of the mean hierarchy.

\footnotetext{
${ }^{16}$ Naturally, many respondents occupy an intermediate position, for instance by preferring both classic pop bands and Dutch language singers and disliking classical music and contemporary pop, while producing a hierarchy similar to that of many others.

${ }^{17}$ Formally, the dispersion of a ranking variable cannot be measured with the standard deviation, but it nevertheless gives an enlightening picture (cf. Van Heek et al. 1958: 323 n23).

${ }_{18}$ The percentage of items within 15\% above or below the mean ranges from $93.5 \%$ (Bach) to $26.0 \%$ (André Rieu, see below). 21 out of 29 items score above $50 \%$.

${ }^{19}$ Formally, statistical significance is not applicable in case of non-random samples, but it does provide insight into the relevance of the correlations.
} 
Table 2. Spearman's rho between educational level and the rankings of hierarchy and taste

\begin{tabular}{|c|c|c|}
\hline & Hierarchy $(\mathbf{N}=77)$ & Taste $(\mathrm{N}=85)$ \\
\hline J.S. Bach & $.40^{* * *}$ & $.44^{* * *}$ \\
\hline W.A. Mozart & $.30^{* *}$ & $.37 * * *$ \\
\hline A. Vivaldi & .13 & $.37 * *$ \\
\hline A. Schönberg & .21 & $.41 * *$ \\
\hline Johann Strauss II & -.14 & .02 \\
\hline Jacques Brel & .18 & .17 \\
\hline Ella Fitzgerald & .22 & .18 \\
\hline The Beatles & -.14 & -.17 \\
\hline Glenn Gould & $.48^{* *}$ & $.42^{*}$ \\
\hline John Coltrane & .05 & .11 \\
\hline Aretha Franklin & .03 & -.06 \\
\hline Wibi Soerjadi & -.19 & -.10 \\
\hline Ramses Shaffy & .10 & .04 \\
\hline Pink Floyd & .09 & .21 \\
\hline Rolling Stones & .08 & .03 \\
\hline Tori Amos & .01 & -.00 \\
\hline Norah Jones & .21 & -.07 \\
\hline Radiohead & .23 & .16 \\
\hline$\overline{\mathrm{ABBA}}$ & $-.33 * *$ & $-.48^{* * *}$ \\
\hline André Rieu & $-.32 * *$ & -.21 \\
\hline Céline Dion & -.22 & $-.48^{* * *}$ \\
\hline Tiësto & -.01 & .03 \\
\hline Marco Borsato & -.16 & $-.39 * * *$ \\
\hline Metallica & .07 & -.08 \\
\hline Dolly Parton & .08 & -.11 \\
\hline Britney Spears & .01 & -.04 \\
\hline 50 Cent & .00 & -.25 \\
\hline André Hazes & -.15 & -.18 \\
\hline Frans Bauer & $-.32 * *$ & $-.38 * * *$ \\
\hline
\end{tabular}

(The four items that less than half of the respondents included are printed in italics.)

${ }^{*} p<.05 ;{ }^{* *} p<.01 ; * * * p<.001$

For comparative reasons, let us first look at the taste ranking in the right column. In line with other research (Bourdieu, 1984; Peterson and Kern, 1996; etc.), many classical music items correlate positively with level of education: the three main composers (Bach, Mozart and Vivaldi) and the two less well-known items (Schönberg and Gould). Some other classical music items, however, do not correlate with educational level, nor do the jazz and chanson items. Four items correlate negatively with education: two of the Dutch language singers and two commercial pop items. ${ }^{20}$

Regarding the perceived hierarchies, however, four of these nine correlations do not appear. The correlations that do remain - though most of them less strong - regard Bach, Mozart and Gould positively, and ABBA and Bauer negatively. On the other hand, André Rieu is now added to the list. Qualitative analysis shows that lesseducated respondents, without significantly liking him more, perceive this violinist and conductor as higher on the status ladder (perceiving him as an exponent of classical music) than well-educated respondents do (who regard his interpretations as simplifications and who associate him with his lower status audience). Different hierarchical rationales - in this case genre, complexity and audience - collide.

Hence, even within the low dispersion of the top and bottom items, there is variation that is related to educational level. At the top of the hierarchy, this can partly be explained with the explicit consecration of Bach as the most important composer by the (often well-educated) classical music lovers, whereas the (often less-educated) non-connoisseurs frequently group all composers together or rank them randomly.

The strong correlation with items at both ends of the hierarchy is partially caused by three less-educated individuals, who produced an entirely inverted hierarchy. ${ }^{21}$ They can be recognized as the outliers at the bottom of Figure 1b. Their comments suggest that they interpreted the concepts differently, perceiving high culture as what is most popular among the general public. Considering the missing values among several other less-educated respondents and this group's underrepresentation in the quota sample, these exceptions to the rule must be taken

\footnotetext{
${ }^{20}$ Not all items are linearly distributed, which means that some items are preferred or disliked more by respondents with an intermediate educational level. The same counts for the correlations with age.

${ }^{21}$ Excluding these three statistical outliers from analysis gives weaker correlations; Mozart loses statistical significance.
} 
Table 3. Pearson's $r$ between age and the rankings of hierarchy and taste

\begin{tabular}{|c|c|c|}
\hline & Hierarchy $(\mathbf{N}=77)$ & Taste $(\mathrm{N}=85)$ \\
\hline J.S. Bach & .04 & $.44^{* * *}$ \\
\hline W.A. Mozart & -.11 & $.48^{* * *}$ \\
\hline A. Vivaldi & .03 & $.45^{* * *}$ \\
\hline A. Schönberg & .03 & .22 \\
\hline Johann Strauss II & -.19 & $.47 * * *$ \\
\hline Jacques Brel & -.10 & .08 \\
\hline Ella Fitzgerald & $-.30^{*}$ & -.11 \\
\hline The Beatles & $-.29 *$ & $-.29 * *$ \\
\hline Glenn Gould & -.12 & .20 \\
\hline John Coltrane & .13 & -.01 \\
\hline Aretha Franklin & -.22 & -.15 \\
\hline Wibi Soerjadi & .15 & $.51 * * *$ \\
\hline Ramses Shaffy & $-.32 * *$ & .07 \\
\hline Pink Floyd & $-.35^{* *}$ & $-.31 * *$ \\
\hline Rolling Stones & $-.45^{* * *}$ & $-.41 * * *$ \\
\hline Tori Amos & $-.42 *$ & $-.40^{*}$ \\
\hline Norah Jones & -.09 & $-.35 * *$ \\
\hline Radiohead & $-.46^{* *}$ & $-.48^{* *}$ \\
\hline $\mathrm{ABBA}$ & -.02 & -.02 \\
\hline André Rieu & -.08 & $.22^{*}$ \\
\hline Céline Dion & .23 & .12 \\
\hline Tiësto & -.01 & $-.38^{* *}$ \\
\hline Marco Borsato & .13 & $-.35^{* *}$ \\
\hline Metallica & -.24 & $-.43 * *$ \\
\hline Dolly Parton & $-.26^{*}$ & -.15 \\
\hline Britney Spears & .13 & $-.38 * *$ \\
\hline 50 Cent & -.24 & $-.51 * * *$ \\
\hline André Hazes & -.05 & $-.50 * * *$ \\
\hline Frans Bauer & .06 & -.11 \\
\hline
\end{tabular}

(The four items that less than half of the respondents included are printed in italics.)

${ }^{*} p<.05 ;{ }^{* *} p<.01 ;{ }^{* * *} p<.001$

seriously. In a random sample, agreement on cultural hierarchy would most probably be less strong, as would the evidence for Bourdieu's thesis on the recognition of one's own inferiority.

Table 3 shows the correlations (Pearson's r) between both rankings and respondents' age. Again starting with taste, significant correlations can be found with no less than eighteen items. Six classical music items are liked more by older people, whereas many (though not all) of the popular music and Dutch language items are liked more by younger people. Even items that are mostly not familiar among the older cohorts, such as Radiohead and 50 Cent, show a strong age effect among those who do know them.

The correlations between age and hierarchical perceptions show a different picture. There is no correlation regarding the classical music items: although $\mathrm{Bach}$ is preferred much more by older cohorts, respondents of all age groups equally perceive his music as high culture. A similar effect can be observed in the lower half of the hierarchy: some Dutch language singers (André Hazes, Marco Borsato) and contemporary popular music items (50 Cent, Britney Spears, Metallica, Tiësto, Norah Jones) are liked more by younger respondents but perceived as equally low (or middlebrow) culture by all age groups.

Significant correlations between age and hierarchy do exist - sometimes even stronger than between age and taste - with regard to several popular music items that are perceived as higher on the ladder by younger respondents. First, this regards two relatively contemporary items (Radiohead, Tori Amos) that are perceived as 'authentic', 'complex' or 'innovative', compared to 'commercial' items that do not show an age effect. Respondents from the youngest birth cohort more often apply an aesthetic disposition than older respondents do, who favour classic canonical criteria such as morality and seniority (more on this distinction: Van den Haak, 2018a). Ronald, for instance, who was 35 years old at the time of the interview, explains his top position for Radiohead as follows:

"There are only a few bands that have innovated and changed music and that gave it such a personal feel and artistic dimension, so I don't think it's unreasonable to put it next to someone like Bach. Because, in our time, they have been pioneering." 
Ronald is quite extreme in this position, as the 10 academically trained respondents from the youngest cohort put Radiohead on average on the tenth position (eight places higher than in the sample as a whole), but the point is that he argues its top position as a possibility.

Second, one jazz item and five popular music items that are somewhat older (Ella Fitzgerald, Beatles, Rolling Stones, Pink Floyd, Dolly Parton, Ramses Shaffy) are also perceived as higher in the hierarchy by younger respondents. These artists were most popular before the youngest respondents were born. Apparently, younger generations are more inclined to retrospectively consecrate (Schmutz, 2005) the music from their parents' youth than individuals from their parents' generation are themselves. It takes some distance to canonise music.

\section{CONCLUSION: A PERSISTENT BUT MORE COMPLEX CULTURAL HIERARCHY}

This article explored the perceptions that people of different backgrounds have of cultural hierarchy, which casts light on the dual relation between taste and hierarchy as a social construction. Moreover, it investigated the salience of cultural hierarchy in an era when the boundaries between high and low culture are often said to have become blurred due to the rise of cultural omnivores. This was researched by means of a ranking task among ninety Dutch people, that compared hierarchical perceptions with taste preferences and dislikes within music.

It teaches us, first, that many perceive a cultural hierarchy, regardless of strong egalitarian feelings that dispute any form of hierarchy. Second, agreement is high on the nature of this hierarchy in broad strokes. Particularly the high status position of classical music and the low position of certain Dutch language singers and some contemporary pop acts are hardly debated. Third, this agreement exists in spite of significant taste differences. Although many perceive their dislikes as low culture, they often do distinguish what's good from what's high. Finally, this agreement is not absolute, as a minority of less educated respondents does not adhere to the dominant logic, and as younger generations tend to canonise 'classical' and 'alternative' exponents of popular culture more than older generations do.

These results imply that the relations between taste, distinction and cultural hierarchy have been disentangled. First, in previous research, hierarchical domains such as 'high culture' were often defined a priori or inferred from taste patterns, rather than put into question. This article showed that the perception of hierarchy can be distinguished from taste itself, but that the mean hierarchy overall corresponds with the taste ranking of welleducated respondents from older cohorts. Even most less-educated respondents, despite having opposite tastes, produce a similar hierarchy and hence recognise the inferior status position of their own tastes, as Bourdieu (1984: 372-396) claimed.

This means, second, that omnipresent notions of the blurring or even disappearing of high-low boundaries are overstated. Contemporary consumers might have broad tastes and they might resist cultural hierarchy and social stratification as such, but most of them still perceive a high-low ranking when asked. Hierarchical perceptions should therefore be differentiated from opinions on hierarchy.

Third, both concepts should also be differentiated from hierarchical practices, which still occur in the form of cultural distinction. As previous research showed, many keep distinguishing good from bad tastes (e.g., Holt, 1998; Jarness, 2015; Van den Haak and Wilterdink, 2019). Increased complexity in such distinction processes results in a more complex and diverse cultural hierarchy. Although the mean perceived hierarchy resembles traditional and common-sense high-low distinctions, there are many deviations, particularly caused by younger cohorts. Their inclination to single out more complex, original, innovative and authentic items within broader genres in popular culture, leads to a higher status for these items, both in reality (as the socially constructed result of distinction processes) and in their perception. Unlike sometimes believed, this is perfectly in line with the thinking of Bourdieu (1984), who stated that individuals with a high volume of cultural capital are inclined to enjoy all kinds of cultural items in an aesthetic way. Similarly, consecrating institutions are able to actually confer status to such items. This does not make cultural hierarchy more coherent, though.

Future research could unravel taste patterns and hierarchical perceptions in a more systematic way, by means of a larger and more random sample than in the qualitative research of which the presented ranking task was a part. Most importantly, this should include more respondents with a lower educational level, as this group was severely underrepresented in the current sample (both due to deliberate choices in the overall research and due to selective non-response). Some of the less-educated in this study were not able to perform the ranking task, whereas three others produced an opposite hierarchy, based on an alternative logic. A more thorough inclusion of this significant group would probably lead to a little less agreement on cultural hierarchy and hence some more deviation from Bourdieu's ideas on their acceptance of others' superiority. Anti-elitist and anti-snobbish attitudes have become widespread in recent times (e.g., Schwarz, 2019), in line with populist discourse.

Future studies could adopt the method of including survey items on the level of artists rather than too broad genres or too narrow artefacts (songs, musical pieces), but including at least two examples per genre is strongly recommended. In the current study, several genres, such as hip hop, were represented by only one item, which 
prevents us from further interpretation of more detailed distinctions based on aesthetic qualities such as perceived complexity and originality.

This study suggests that both Bach, The Beatles and Radiohead can be perceived as high culture, even though this might go against traditional common-sense notions. Along with the emergence and ageing of new welleducated generations, the exact nature of cultural hierarchy will continuously change, without losing its general principle (cf. Hanquinet, 2018). This is something different than the blurring of high and low, even though many interpret the mixing of art forms and the broad tastes of omnivores as such. Defining high culture with rigid genre boundaries does not help us understand the dynamic nature of cultural taste and distinction.

\section{ACKNOWLEDGEMENTS}

The author wishes to thank Giselinde Kuipers and the anonymous reviewers for their valuable comments on previous versions of this article, as well as Nico Wilterdink for his appreciated contribution in earlier stages of the research.

\section{REFERENCES}

Atkinson, W. (2011). The context and genesis of musical tastes: Omnivorousness debunked, Bourdieu buttressed. Poetics, 39, 169-186. https://doi.org/10.1016/j.poetic.2011.03.002

Bachmayer, T., Wilterdink, N. and van Venrooij, A. (2014). Taste differentiation and hierarchization within popular culture: The case of salsa music. Poetics, 47, 60-82. https://doi.org/10.1016/j.poetic.2014.10.004

Baumann, S. (2001). 'Intellectualization and art world development: Film in the United States.' American Sociological Review, 66(3), 404-426. https:// doi.org/10.2307/3088886

Bennett, T., Savage, M., Silva, E., Warde, A., Gayo-Cal, M. and Wright, D. (2009). Culture, class, distinction. London: Routledge. https://doi.org/10.4324/9780203930571

Bourdieu, P. (1984 [1979]). Distinction. A social critique of the judgement of taste. London: Routledge.

Bourdieu, P. (1996 [1992]). The rules of art. Genesis and structure of the literary field. Cambridge: Polity Press.

Brisson, R. (2019). Back to the original omnivore: On the artefactual nature of Peterson's thesis of omnivorousness. Poetics, https://doi.org/10.1016/j.poetic.2019.03.004

Bryson, B. (1996). "Anything but heavy metal." Symbolic exclusion and musical dislikes. American Sociological Review, 61(5), 884-899. https:// doi.org/10.2307/2096459

Coulangeon, P. (2013a). Changing policies, challenging theories and persisting inequalities: Social disparities in cultural participation in France from 1981 to 2008 . Poetics, 41, 177-209. https://doi.org/10.1016/j.poetic.2012.12.003

Coulangeon, P. (2013b). The omnivore and the 'Class Defector'. Musical taste and social mobility in contemporary France. Notes \& Documents, 2013-03, Paris, OSC, Sciences Po/CNRS.

Elchardus, M. and Siongers, J. (2007). Ethnocentrism, taste and symbolic boundaries. Poetics, 35(4-5), 215-238. https:// doi.org/10.1016/j.poetic.2007.09.002

Elshout, J. (2016). Roep om respect. Ervaringen van werklozen in een meritocratiserende samenleving. Amsterdam: Stichting de Driehoek.

Emmison, M. (2003). Social class and cultural mobility. Reconfiguring the cultural omnivore thesis. Journal of Sociology, 39(3), 211-230. https://doi.org/10.1177/00048690030393001

Friedman, S. (2012). Cultural omnivores or culturally homeless? Exploring the shifting cultural identities of the upwardly mobile. Poetics, 40, 467-489. https://doi.org/10.1016/j.poetic.2012.07.001

Frith, S. (1996). Performing rites: On the value of popular music. Cambridge: Harvard University Press.

Hanquinet, L. (2018). 'But is it good?' Why aesthetic values matter in sociological accounts of tastes. Journal of Cultural Analysis and Social Change, 3(2), 09. https://doi.org/10.20897/jcasc/3990

Holt, D. B. (1997). Distinction in America? Recovering Bourdieu's theory of taste from its critics. Poetics, 25(2-3), 93-120. https:// doi.org/10.1016/S0304-422X(97)00010-7

Holt, D. B. (1998). Does cultural capital structure American consumption? Journal of Consumer Research, 25(1), 1-25. https://doi.org/10.1086/209523

Janssen, S., Verboord, M. and Kuipers, G. (2011). Comparing cultural classification. High and popular arts in European and U.S. elite newspapers, 1955-2005, in J. Rössel and G. Otte (eds.), Lebensstilforschung. Special edition of Kölner Zeitschrift für Soziologie und Soz̨ialpsychologie, 51 (pp. 139-168).

Jarness, V. (2015). Modes of consumption: From 'what' to 'how' in cultural stratification research. Poetics, 53, 6579. https://doi.org/10.1016/j.poetic.2015.08.002 
Kuipers, G. (2006). Good humor, bad taste. A sociology of the joke. Berlin: Mouton de Gruyter. https://doi.org/10.1515/9783110898996

Lamont, M. (2000). The dignity of working men. Morality and the boundaries of race, class, and immigration. New York: Russel Sage Foundation / Cambridge: Harvard University Press.

Lena, J. and Peterson, R.A. (2008). Culture as classification: Types and trajectories of music genres. American Sociological Review, 73(5), 697-718. https:/ / doi.org/10.1177/000312240807300501

Levine, L. W. (1988). Highbrow / lowbrow: the emergence of cultural hierarchy in America. Cambridge / London: Harvard University Press.

López Sintas, J. and García Álvarez, E. (2004). Omnivore versus univore consumption and its symbolic properties: evidence from Spaniards' performing arts attendance. Poetics, 32(6), 463-483. https://doi.org/10.1016/S0304$422 \mathrm{X}(04) 00055-5$

Michael, J. (2017). Negotiating normaly and difference: Discourses on cultural taste and symbolic boundaries (PhD thesis), Erasmus University Rotterdam.

Nagel, I., Ganzeboom, H. B. G. and Kalmijn, M. (2011). Bourdieu in the network: The influence of high and popular culture on network formation in secondary school, in J. Rössel and G. Otte (eds.), Lebensstilforschung. Special edition of Kölner Zeitschrift für Soziologie und Sozialpsychologie, 51 (pp. 424-446).

Ollivier, M. (2008). Modes of openness to cultural diversity: Humanist, populist, practical, and indifferent. Poetics, 36(2-3), 120-147. https://doi.org/10.1016/j.poetic.2008.02.005

Peters, J., van Eijck, K. and Michael, J. (2018). Secretly serious? Maintaining and crossing cultural boundaries in the karaoke bar through ironic consumption. Cultural Sociology, 12(1), 58-74. https://doi.org/10.1177/1749975517700775

Peterson, R. A. (1992). Understanding audience segmentation: From elite and mass to omnivore and univore. Poetics, 21(4), 243-258. https:// doi.org/10.1016/0304-422X(92)90008-Q

Peterson, R. A. and Kern, R. (1996). Changing highbrow taste: From snob to omnivore. American Sociological Review, 61(5), 900-907. https:// doi.org/10.2307/2096460

Peterson, R. A. and Simkus, A. (1992). How musical tastes mark occupational status groups. In M. Lamont and M. Fournier (eds.), Cultivating differences. Symbolic boundaries and the making of inequality (pp. 152-186). Chicago: The University of Chicago Press.

Prieur, A., Rosenlund, L., and Skjott-Larsen, J. (2008). Cultural capital today: A case study from Denmark. Poetics, 36(1), 45-71. https://doi.org/10.1016/j.poetic.2008.02.008

Prieur, A. and Savage, M. (2013). Emerging forms of cultural capital. European Societies, 15(2), 246-267. https:/ / doi.org/10.1080/14616696.2012.748930

Robette, N. and Roueff, O. (2014). An eclectic eclecticism: Methodological and theoretical issues about the quantification of cultural omnivorism. Poetics, 47, 23-40. https://doi.org/10.1016/j.poetic.2014.10.002

Savage, M. (2006). The musical field. Cultural Trends, 15(2/3), 159-174. https://doi.org/10.1080/09548960600712975

Schmutz, V. (2005). Retrospective cultural consecration in popular music: Rolling Stone's Greatest Albums of All Time. American Behavioral Scientist, 48(11), 1510-1523. https:/ / doi.org/10.1177/0002764205276617

Schulze, G. (1992). Die Erlebnisgesellschaft. Kultursoziologie der Gegenwart. Frankfurt: Campus.

Schwarz, O. (2019). 'Everything is designed to make an impression': The moralisation of aesthetic judgement and the hedonistic ethic of authenticity. European Journal of Cultural Studies, 22(4), 399-415. https://doi.org/10.1177/1367549419861629

Sixma, H. and Ultee, W. (1987). Een beroepsprestigeschaal voor Nederland in de jaren tachtig. Mens en Maatschappij, 58(4), 360-382.

Thornton, S. (1995). Club cultures: Music, media, and subcultural capital. Cambridge: Polity Press.

Van den Haak, M. (2014). Disputing about taste. Practices and perceptions of cultural hierarchy in the Netherlands. PhD thesis, University of Amsterdam.

Van den Haak, M. (2018a). High culture unravelled. A historical and empirical analysis of contrasting logics of cultural hierarchy. Human Figurations, 7(1).

Van den Haak, M. (2018b). Esthetische omnivoren. Een vergelijking tussen hoog- en laagopgeleiden in het gebruik van esthetische repertoires. Sociologie, 14(2/3), 97-117. https://doi.org/10.5117/SOC2018.2/3.003.HAAK

Van den Haak, M. and Wilterdink, N. (2019). Struggling with distinction. How and why individuals switch between cultural hierarchy and equality. European Journal of Cultural Studies, 22(4), 416-432. https:// doi.org/10.1177/1367549419861632

Vander Stichele, A. (2007). De culturele alleseter? Een kwantitatief en kwalitatief onderzoek naar 'culturele omnivoriteit' in Vlaanderen ( $\mathrm{PhD}$ thesis), Catholic University Leuven.

Van Eijck, K. (2000). Richard A. Peterson and the culture of consumption. Poetics, 28(2-3), 207-224. https:// doi.org/10.1016/S0304-422X(00)00022-X 
Van Eijck, K. (2001). Social differentiation in musical taste patterns. Social Forces, 79(3), 1163-1184. https://doi.org/10.1353/sof.2001.0017

Van Eijck, K., de Haan, J. and Knulst, W. (2002). Snobisme hoeft niet meer. De interesse voor hoge cultuur in een smaakdemocratie. Mens en Maatschappij, 77(2), 153-177.

Van Eijck, K. and Lievens, J. (2008). Cultural omnivorousness as a combination of highbrow, pop, and folk elements. Poetics, 36(2-3), 217-242. https://doi.org/10.1016/j.poetic.2008.02.002

Van Eijk, G. (2013). Hostile to hierarchy? Individuality, equality and moral boundaries in Dutch class talk. Sociology, 47, 526-541. https://doi.org/10.1177/0038038512453788

Van Heek, F. and Vercruijsse, E. V. W. (1958). De Nederlandse beroepsprestige-stratificatie. In F. van Heek, et al. Sociale stijging en daling in Nederland (pp. 9-48). Leiden: Stenfert Kroese.

Van Venrooij, A. and Schmutz, V. (2010). The evaluation of popular music in the United States, Germany and the Netherlands: A comparison of the use of high art and popular aesthetic criteria. Cultural Sociology, 4(3), 395-421. https:// doi.org/10.1177/1749975510385444

Warde, A. (2011). Cultural hostility re-considered. Cultural Sociology, 5(3), 341-366. https://doi.org/10.1177/1749975510387755

Wouters, C. (2007). Informalization: Manners and Emotions since 1890. London: Sage. 